\title{
Moral reasoning and emotion attributions of adolescent bullies, victims, and bully-victims
}

\author{
Sonja Perren ${ }^{1 *}$, Eveline Gutzwiller-Helfenfinger ${ }^{2}$, Tina Malti ${ }^{3}$ \\ and Shelley Hymel ${ }^{4}$ \\ 'Jacobs Center for Productive Youth Development, University of Zürich, \\ Switzerland \\ ${ }^{2}$ University of Teacher Education of Central Switzerland, Lucerne, Switzerland \\ ${ }^{3}$ University of Toronto Mississauga, Canada \\ ${ }^{4}$ Department of Educational and Counselling Psychology and Special Education, \\ University of British Columbia, Canada
}

\begin{abstract}
This study investigated different facets of moral development in bullies, victims, and bully-victims among Swiss adolescents. Extending previous research, we focused on both bullying and victimization in relation to adolescents' morally disengaged and morally responsible reasoning as well as moral emotion attributions. A total of 516 adolescents aged 12-18 (57\% females) reported the frequency of involvement in bullying and victimization. Participants were categorized as bullies (14.3\%), bully-victims (3.9\%), and victims $(9.7 \%)$. Moral judgment, moral justifications, and emotion attributions to a hypothetical perpetrator of a moral transgression (relational aggression) were assessed. Bullies showed more morally disengaged reasoning than non-involved students. Bullyvictims more frequently indicated that violating moral rules is right. Victims produced more victim-oriented justifications (i.e., more empathy) but fewer moral rules. Among victims, the frequency of morally responsible justifications decreased and the frequency of deviant rules increased with age. The findings are discussed from an integrative moral developmental perspective.
\end{abstract}

Over the last few years, it has been repeatedly argued that many bullies do not demonstrate deficits in social intelligence but may have deficits regarding their morality (Gini, 2006; Hymel, Schonert-Reichl, Bonanno, Vaillancourt, \& Henderson, 2010; Sutton, Smith, \& Swettenham, 1999). Bullying - a specific subtype of aggressive behaviour is characterized by certain repetitiveness and an imbalance of power between the bully and the victim (Olweus, 1991). Aggressive acts against the victim may be direct (physical, verbal, etc.) or indirect (isolation, relational aggression, rumours, etc.), and they often include humiliating elements. Although moral development research and

\footnotetext{
* Correspondence should be addressed to Sonja Perren, Jacobs Center for Productive Youth Development, University of Zürich, Culmannstrasse 1, CH-8006 Zürich, Switzerland (e-mail: perren@jacobscenter.uzh.ch).
} 
bullying research have developed rather independently, recent integrative models in developmental moral theory have emphasized the need to investigate both moral cognition and moral affect in understanding individual differences in behaviours such as bullying and aggression (Arsenio \& Lemerise, 2004; Malti \& Krettenauer, 2011). Associations between bullying and morality have so far been discussed mainly from the perspective of moral disengagement theory (Bandura, 2002). According to these models, aggression and bullying are associated with certain kinds of moral reasoning because it helps individuals to avoid feelings of guilt (Arsenio, Gold, \& Adams, 2006; Malti, Gasser, \& Gutzwiller-Helfenfinger, 2010).

In the current study, we apply the conceptual framework of moral development as used in 'happy victimizer' research to investigate links between moral emotions, moral reasoning, and bullying (for reviews, see Arsenio et al., 2006; Krettenauer, Malti, \& Sokol, 2008). Moreover, we integrate some conceptual ideas from moral disengagement research into our framework (Bandura, 2002; Menesini et al., 2003). The first aim of the current study is to expand previous research by investigating associations between bullying and moral versus amoral emotions as well as different facets of morally disengaged and morally responsible justifications, respectively.

As bullying is defined as aggressive behaviour that is directed towards a specific victim, the roles of both targeted individuals and perpetrators are important considerations in order to fully understand the phenomenon. Accordingly, the second aim of our study was to investigate not only links between bullying and moral development, but also between victimization experiences and moral reasoning and emotion attributions.

\section{Bullying, moral reasoning, and emotion attributions}

A considerable body of research exists on the relationship between morally (ir)responsible reasoning and aggressive and delinquent behaviour (see Arsenio et al., 2006; Krettenauer et al., 2008; Tisak, Tisak, \& Goldstein, 2006). For example, Paciello, Fida, Tramontano, Lupinetti, and Caprara (2008) documented stable longitudinal associations between chronic aggression and moral disengagement in a sample of 366 adolescents aged $12-18$ years.

However, few studies have investigated the specific link between bullying, moral reasoning, and moral emotion attributions (see Hymel et al., 2010) and most have focused primarily on childhood (e.g., Gasser \& Keller, 2009). Some studies have used the conceptual framework of moral disengagement to investigate moral reasoning patterns among bullies. For example, Hymel, Rocke Henderson, and Bonanno (2005) found that 12- to 16-year-olds in Canada who reported that they were bullying others extensively showed greater moral disengagement in their attitudes and beliefs than students who sometimes or never bullied others. The associations between bullying and moral disengagement have also been demonstrated in children. In a sample of 8- to 11-year-olds in Italy, Gini (2006) found that youth who bullied others, as well as those who reinforced such behaviour and/or assisted the bully, showed significantly more moral disengagement than victims, uninvolved children, and defenders of the victims. Finally, a recent study by Pornari and Wood (2010) showed that moral disengagement is not only associated with traditional peer aggression (bullying) but also with cyber aggression.

All of these studies used self-report questionnaires to assess moral reasoning - mostly the original or adapted version of the Bandura questionnaire (Caprara, Pastorelli, \& 
Bandura, 1995). Therefore, we do not know the relative importance of morally disengaged strategies as compared to other types of moral reasoning strategies for bullying behaviour. In the current study, we also methodologically extend these different strands of research by using a production measure that assesses adolescents' morally disengaged and morally responsible justifications in a more differentiated way than self-report questionnaire measures. Production measures have typically been used in developmental research within the 'happy victimizer' paradigm, describing the phenomenon that even though children understand the validity of moral rules, they still attribute positive emotions to transgressors (Krettenauer et al., 2008). The use of such a production measure is supported by an early study by Gavaghan, Arnold, and Gibbs (1983). They found that juvenile delinquents showed lower moral development in a production measure than non-delinquents, whereas a recognition measure did not discriminate between the groups. Hence, we can assume that different aspects of moral understanding are being tapped into, depending on the demands of the task (selecting a response category vs. active reasoning).

However, as far as we know, only two studies have used production measures to investigate associations between moral reasoning and bullying. In the first study, Menesini and collaborators (2003) collected moral emotion attributions and justifications for a bully in a fictitious story from a sample of 10-and 13-year-olds. The authors showed that bullies attributed pride and indifference to the wrongdoer more frequently than did either victims or uninvolved children. Bullies thought about these feelings mainly from an egocentric point of view, and their thinking centred on receiving personal benefit and profiting from their negative actions. Another study of 9-year-old children used a similar measure (Gutzwiller-Helfenfinger et al., 2011) and showed that children who were more frequently involved in bullying produced more morally disengaged and fewer morally responsible justifications. This line of research is in keeping with related studies of moral reasoning and aggression revealing that children and adolescents involved in aggression display lower morally responsible reasoning and higher egocentric reasoning (Malti \& Keller, 2009; Stams et al., 2006).

We aimed to replicate and extend these previous findings on bullying and moral reasoning by using a production measure rather than self-reports in a sample of 12 to 18-year-old adolescents. Because adolescence is understood to be the time when a sense of moral identity and related stability in moral action tendencies establish (Keller, 2004), we expected that the relationships between bullying and moral reasoning might be stronger than those reported for childhood.

\section{Victimization, moral reasoning, and emotion attributions}

Almost no study has focused on the relationships between victimization experiences and moral development so far. Conceptually, researchers have proposed that people with low power and low status in the social hierarchy may be more aware of what makes transgressions wrong (Turiel, 2002). A recent study by Malti, Killen, and Gasser (in press) indicates that adolescents in a minority position are more sensitized towards issues of fairness and equality in situations entailing social exclusion than adolescents of a majority group (see also Killen, Lee-Kim, McGlothlin, \& Stangor, 2002). Based on this theoretical assumption, it is likely that early experiences of unfair treatment by being victimized may increase sensitivity towards norms of fairness and care and enhance moral responsibility. Therefore, individuals who are victims of aggression or bullying may display higher moral responsibility when justifying their behaviours 
and experience moral emotions (e.g., being ashamed) because they understand the consequences of moral rule violations and are showing empathic concern towards the victim. On the other hand, students who are frequently victimized tend to show a tendency towards self-blame (Graham \& Juvonen, 1998). This finding offers an alternative explanatory approach, stating that it is possible that victims begin to think that bullying is morally right (because they themselves or others as victims did something wrong) and thus also show less moral emotions and more morally disengaged reasoning.

Regarding associations between victimization and moral reasoning in adolescence, empirical findings are rather limited. Hymel et al. (2005) found that morally disengaged reasoning patterns did vary as a function of how often students had been victimized, but only among 12- to 16-year-olds who reported that they sometimes bullied others (not among those who frequently or never bullied others): The more victimization students experienced, the fewer morally disengaged strategies they endorsed. GutzwillerHelfenfinger et al. (2011) found that higher levels of victimization in kindergarten predicted higher moral reasoning in mid-childhood (when controlling for bullying). Likewise, Pornari and Wood (2010) found that higher peer victimization was associated with lower moral disengagement, when controlling for own aggressive behaviour. In contrast, two other studies that included victimization found no differences between (nonaggressive) victims and non-involved children/adolescents (e.g., Gini, 2006; Menesini et al., 2003) with respect to moral reasoning.

Related studies on the links between victimization and empathy/sympathy have argued that victimized children and adolescents may lack the social-cognitive preconditions for displaying empathy towards needy peers or related moral emotions, as they have been shown to have problems with understanding the mind of other children (Gini, 2006). Malti, Perren, and Buchmann (2010) reported negative relations between peer victimization and empathy in a sample of 6-to 7-year-old children. In contrast, it is also reasonable to argue that victimized children display more empathy because they are particularly sensitive to the emotional consequences of rule transgressions. The latter argument is indirectly supported by Garner and Lemerise (2007), who showed that in preschool age children, victimization was positively associated with global knowledge of the emotional situation of provoking peers and the attribution of sorrow to them. Similarly, Menesini et al. (2003) found that preadolescent victims attributed indifference and pride to the victimizer less frequently than bullies did. This knowledge of emotions is an important social-cognitive prerequisite of empathy. Given the inconsistent findings reported on relations between victimization and moral emotions, we sought to investigate how victimization is associated with the attribution of moral emotions.

\section{Research questions}

To summarize, the current study had two aims. First, we investigated whether bullying is associated with different facets of moral reasoning and moral emotions. Based on research on the association between moral reasoning or moral disengagement on the one hand and bullying or aggression on the other hand, we hypothesized that adolescents who are frequently involved in bullying others would produce more morally disengaged justifications, fewer morally responsible justifications, fewer moral, and more amoral emotions. 
Second, we investigated whether victims of bullying also differ with respect to moral reasoning and emotion attributions as compared to non-involved adolescents. Several studies have demonstrated the importance of differentiating between non-aggressive and aggressive victims because bully-victims (aggressive victims) show the most problematic deficits regarding their social skills, socio-cognitive competences, and mental health (Stassen Berger, 2007). As they share some attributes with bullies and some with victims, we might assume that they also show higher levels of morally disengaged reasoning. On the other hand, they frequently experience victimization themselves, which might sensitize them to a different perspective and moral understanding. We had no directed hypothesis on the relation between victimization and moral emotion attributions, as the few previous studies have revealed inconsistent findings.

Due to general age trends in moral reasoning (Keller, Edelstein, Schmid, Fang, \& Fang, 1998) and in moral disengagement (Paciello et al., 2008), we also investigated age differences. Specifically, we investigated whether the association between bullying/victimization and moral reasoning is moderated by age. Finally, given previous evidence that girls show fewer morally disengaged reasoning strategies and more moral emotions (Paciello et al., 2008; Tangney \& Dearing, 2002) we also investigated gender differences. The hypothetical scenario we used to assess moral justifications and emotions describes a girl behaving relationally aggressively towards a boy. Therefore, we analysed whether gender moderated the investigated associations.

\section{Method}

\section{Participants}

Twenty-six school classes (grades 7-12) in the city of St. Gallen, Switzerland participated in the study. Schools and participating classrooms were selected to represent all city districts and all school types at the secondary level in Switzerland.

Following Swiss legislation, permission from the respective school councils to conduct the study was obtained. Afterwards, teachers from the selected schools volunteered to participate with their classes. Students were informed about the study and procedures and had the opportunity to withdraw from participation without penalty. Participating school classes received a voucher for books and media worth 50 Swiss Franks. Teachers and students received general feedback about the occurrence of bully/victim problems in their classes and an information flyer indicating potential contact addresses for youths in trouble.

Although no student actively refused to participate in the study, six questionnaires were eliminated due to missing or nonsense information. Another 16 students did not participate due to their absence on the day of the study. The final sample included 516 adolescent participants ( 222 boys). The mean age was $15.18(S D=1.80)$. Twenty-one participants did not indicate their age; these missing values were replaced with the mean age of their respective school class.

The participating school classes represent all three school types in Switzerland: 'Realschule' with basic classes (low-level school): $n=113$, 'Sekundarschule' with broader classes (average-level school): $n=121$ and 'Gymnasium' with advanced classes (high-level school): $n=282$. Due to the highly canalized educational system of Switzerland, after grade 9, only adolescents in the higher achievement level are enrolled in a full-time schooling environment (high-level schools). The others are in vocational training that combines part-time formal schooling and practical work. Therefore, age 
and achievement level are confounded, making it necessary for us to control for school type, in addition to age.

\section{Procedure}

Measures were obtained from a questionnaire administered to the participants in the school setting during normal school hours. Research assistants distributed the questionnaires, explained the procedure, and answered students' questions. The questionnaire contained questions about bullying (perpetration) and victimization, moral development, social competence, and well-being/ health. In the current paper, only the first two aspects are analysed.

\section{Measures}

Bullying and victimization

Participants reported on the frequency of bullying and victimization during the last 3 months $(0=$ never, $1=1-2$ times, $2=$ once a week, $3=$ several times a week, $4=$ several times a day). Each scale consisted of five items covering specific negative behaviours (verbal aggression, physical aggression, exclusion, indirect aggression, and property-related behaviours) (Perren \& Alsaker, 2006).

Based on the definition of bullying as repeated harmful acts (Olweus, 1991), we took the frequency of the behaviour into account to categorize children into bullies, bullyvictims, and victims. In line with other studies a cut-off of 'once a week' was used for categorization (Perren, Dooley, Shaw, \& Cross, 2010; Perren \& Hornung, 2005; Stassen Berger, 2007). Children were categorized as bullies if they reported bullying others at least once a week on any of the items but who also reported that they were victimized never or only 1-2 times $(n=74)$. Victims reported being victimized once a week or more but also reported that they never or 1-2 times bullied others $(n=50)$. Bully-victims were victimized and bullied others at least once a week $(n=20)$. All other adolescents are considered to be non-involved $(n=372)$.

\section{Moral emotions and moral reasoning}

Moral justifications were assessed using a production measure that has been utilized in happy victimizer research (Krettenauer et al., 2008). Participants answered questions regarding a hypothetical moral rule violation (relational aggression).. The vignette described a protagonist (Johanna) who - by text message - intentionally misinforms a classmate she dislikes (Boris) about where a group of classmates is going to meet to spend the afternoon together. The vignette was followed by questions assessing the participant's moral rule understanding (Q1: Is it right to give wrong directions or not? Why?); emotion attributions to hypothetical victimizer (Q2: How does Johanna feel? Why?), and moral evaluation of emotion attributions to hypothetical victimizer (Q3: Is it right or not that Johanna feels this way? Why?; see Malti, Gummerum, Keller, \& Buchmann, 2009). Except for emotion attributions, questions were open-ended. Moral justifications were established on the basis of students' written answers to the 'why' questions. The interviews were rated by two well-trained coders who were blind to the other data of the study. Inter-rater reliability ( $20 \%$ of interviews) was high (intraclasscorrelations of the seven scales used in the subsequent analyses ranged between .84 and 1.00, mean ICC: 0.90). 
Moral judgment (question I)

When asked to evaluate the perpetrator's behaviour (giving the wrong directions), participants indicated that the perpetrator's behaviour was right or wrong (or both).

\section{Emotion attributions (question 2 and 3)}

In the case of emotion attributions, children were provided with seven affect labels (i.e., the seven basic emotions: sad, angry, happy, proud, indifferent, anxious, or ashamed) and could choose one or several of these options (Malti, Gasser et al., 2010). Emotions attributions were coded as moral (e.g., feeling ashamed after a transgression) versus amoral (e.g., feeling proud after a transgression). As children could nominate more than one emotion (12\% indicated two or more emotions) and sometimes nominated mixed emotions (5\% children indicated moral and amoral emotions within the same question), two separate scores for being moral and amoral were computed. Regarding question 3 , emotion attributions were only counted if a child judged the emotions she/he attributed to the perpetrator in question 2 as 'right'.

Feeling ashamed and anxious are considered as moral (score 2 for moral), sad is considered as partly moral (score 1). First, we analysed whether a child indicated at least one (partly) moral emotion. The most extreme answer was used for scoring. Children received for each question a score of 2 (moral), 1 (partly moral), or 0 (no moral emotions).

Feeling happy and proud are considered as amoral (score 2 for amoral), indifferent is considered as partly amoral (score 1 for amoral). Then, we analysed whether a child indicated at least one (partly) amoral emotion. The most extreme answer was used for scoring. Children received for each question a score of 2 (amoral), 1 (partly amoral), or 0 (no amoral emotion).

Feeling angry was considered neutral and was not included in the score of moral or amoral emotions. Mean scores for question 2 and 3 were used, with scores ranging from 0 to 2 .

Moral justifications (questions I, 2, and 3)

Moral justifications were coded according to a set of pre-defined categories (see Table 1) consisting of commonly used justification categories (e.g., Malti, Perren et al., 2010b; Nunner-Winkler, 1999) and specific moral disengagement strategies (Bandura, 2002). In a second step, these categories were combined into two overall scales and five subscales. Based on Menesini et al.'s (2003) conceptual model, moral justifications were coded as morally responsible or morally disengaged. The subscales were also built on the basis of Menesini et al.'s (2003) suggestion. We differentiated between (a) egocentric justifications (reciprocity vs. egocentric disengagement), (b) rule-orientation (moral vs. deviant), and (c) empathy (or lack thereof) for both morally responsible and morally disengaged justifications. Table 1 describes the (sub)scales and their corresponding categories.

The scores for the (sub)scales were first computed for each question separately. If one of the listed categories was mentioned by the participants, he/she received a score of 1 for this specific (sub)scale. For example, if a participant produced at least one deviant rule in a specific question, a score of 1 was assigned to the deviant rules scale. Scores were summed across all three questions, thus scores ranged from 0 to 3 for morally responsible and for disengaged justifications (two overall and five subscales), respectively. 
Table 1. Moral justification categories and scales

Morally responsible justifications

Reciprocity (subscale)

- Reciprocity of morality (e.g., 'If Johanna had received a text message like this she would not be very happy herself.)

Moral rules (subscale)

- Rule-oriented justifications (e.g., 'Because this is just not fair'.)

- Conscience (e.g., 'Maybe she realized that it was wrong to [...], she is certainly reproaching herself for that'.)

- Moral person (e.g., 'If you don't want him there, you can tell him so openly and honestly'.)

- Moral self (e.g., 'I would have the courage to tell people what I think to their face. To do it this way is cowardly'.)

\section{Empathy (subscale)}

- Victim-oriented justifications (e.g., 'The boy then goes to the meeting point and no one is there. This is mean, degrading, and can hurt a person deeply')
Morally disengaged justifications

Egocentric reasoning (subscale)

- Hedonistic-peers (e.g., '... but I can imagine very well her feeling proud! in front of her friends!')

- Hedonistic-sadistic (e.g., 'It does her good to see how Boris is making a fool of himself!')

- Hedonistic-self (e.g., 'Maybe she feels like this because now she feels strong and untouchable'.)

- Hedonistic-unelaborated (e.g., 'Everybody is happy about getting what he wants'.)

- Euphemistic language (e.g.. 'That was only meant for fun'.)

- Minimizing/distorting consequences (e.g., 'The child also thought it was fun'.)

- Personal dislike (e.g., 'Cause she doesn't like Boris and doesn't care about him'.)

Deviant rules (subscale)

- Amoral justifications (e.g., 'The other child would have been in their way'.)

- Attributions of blame (e.g., 'It's the child's fault if he believes that nonsense about the wrong meeting point'.)

- Advantageous comparisons (e.g., 'He could have beaten up the other child, that would have been worse'.)

- Displacement of responsibility (e.g., 'His friends should have made sure he went to the right place'.)

- Diffusion of responsibility (e.g., 'All children said they did not want him'.)

Lack of empathy

- Dehumanization of the victim (e.g., 'She is such a stupid cow'.)

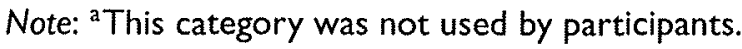

\section{Results}

First, we present descriptive results regarding the moral justifications produced by the participants and explore bivariate associations. Second, we describe results of multivariate analyses examining differences between bullies, bully-victims, victims, and non-involved children regarding their emotion attributions and moral justifications. 
Table 2. Frequencies (\%) of morally responsible and morally disengaged justifications

\begin{tabular}{lccc}
\hline & \multicolumn{3}{c}{ Question context } \\
\cline { 2 - 4 } & Rule & $\begin{array}{c}\text { Emotion attribution } \\
\text { to victimizer }\end{array}$ & $\begin{array}{c}\text { Judgment about } \\
\text { victimizers' emotions }\end{array}$ \\
& $(\mathrm{Q} 1)$ & $(\mathrm{Q} 2)$ & $(\mathrm{Q} 3)$ \\
\hline Justification & $77.2 \%$ & $22.2 \%$ & $64.4 \%$ \\
Morally responsible (total) & $5.0 \%$ & $1.5 \%$ & $5.2 \%$ \\
Reciprocity & $49.7 \%$ & $19.0 \%$ & $54.7 \%$ \\
Moral rules & $34.0 \%$ & $3.7 \%$ & $8.7 \%$ \\
Empathy (victim-oriented) & $8.1 \%$ & $64.8 \%$ & $7.2 \%$ \\
Morally disengaged (total) & $5.0 \%$ & $62.9 \%$ & $5.8 \%$ \\
Egocentric disengagement & $3.3 \%$ & $3.1 \%$ & $1.7 \%$ \\
Deviant rules & & &
\end{tabular}

\section{Descriptive results}

\section{Moral judgment}

When asked to evaluate the perpetrator's behaviour (giving the wrong directions), $94 \%$ of participants indicated that the perpetrator's behaviour was wrong, $5 \%$ indicated that it was right to act that way, and $1 \%$ reported that it was both right and wrong.

\section{Moral justifications}

As can be seen in Table 2 , moral responsibility justifications were produced more frequently than moral disengagement justifications. Regarding moral responsibility, most justifications referred to moral rules and empathy. Most moral disengagement justifications were produced in question 2 , which assessed the representation of the perpetrator (how would this person feel and why). Among these, most were egocentric justifications indicating that the perpetrator feels good because she fulfilled some hedonistic needs (see also Table 3).

\section{Moral emotion attributions}

For question $2,23 \%$ of participants attributed at least one moral emotion to the perpetrator (17.4\% reported 'ashamed'). For question 3, 19\% reported at least one moral emotion (15.3\% 'ashamed'). For question $2,78.7 \%$ indicated that the perpetrator feels an amoral emotion (happy: $20.3 \%$, proud: $31.7 \%$, indifferent: $33.5 \%$ ). For question 3, $9.7 \%$ of participants indicated that they thought it right for the perpetrator to have amoral emotions (happy: $2.1 \%$, proud: $1.9 \%$, indifferent: $5.6 \%$ ). Means and standard deviations of the scales are shown in Table 3.

\section{Bivariate analyses}

Next, Pearson correlations and one chi-square test were computed to investigate bivariate associations.

Associations with age, gender, and school type

As shown in Table 4, boys were more frequently victimized and bullied others more frequently than girls. Boys showed lower levels of morally responsible justifications and 
Table 3. Means (and SD) of all study variables by gender

\begin{tabular}{lcc}
\hline & $\begin{array}{c}\text { Girls } \\
(n=294)\end{array}$ & $\begin{array}{c}\text { Boys } \\
(n=222)\end{array}$ \\
\hline $\begin{array}{l}\text { Emotion attributions } \\
\quad \text { Moral }\end{array}$ & $0.42(0.78)$ & $0.35(0.72)$ \\
$\quad$ Amoral & $0.68(0.44)$ & $0.74(0.52)$ \\
Moral justifications $^{\mathrm{b}}$ & $1.88(0.80)$ & $1.41(0.91)$ \\
$\quad$ Morally responsible (total) & $0.17(0.40)$ & $0.04(0.21)$ \\
Reciprocity/responsibility $_{\text {Moral rules }}$ & $1.43(0.87)$ & $0.97(0.88)$ \\
Empathy (victim-oriented) & $0.50(0.63)$ & $0.42(0.62)$ \\
Morally irresponsible (total) & $0.80(0.63)$ & $0.80(0.75)$ \\
Egocentric disengagement & $0.76(0.58)$ & $0.71(0.67)$ \\
Deviant rules & $0.06(0.26)$ & $0.11(0.36)$ \\
Bully/victim problems & & \\
Bullying & $0.26(0.31)$ & $0.44(0.47)$ \\
Victimization & $0.31(0.36)$ & $0.42(0.52)$ \\
\hline
\end{tabular}

Notes: a Scale: $0-2 ;{ }^{b}$ Scale: $0-3$; ' Scale: $0-4$.

produced more deviant rules. The older the students and the higher the school level, the higher the level of morally responsible justifications and moral emotions and the lower the level of peer victimization.

Associations between bullying/victimization and moral reasoning and emotions

Bullying was negatively associated with morally responsible justifications and positively with morally disengaged justifications and amoral emotions. Victimization was also negatively associated with moral responsibility, but no significant associations were found regarding moral disengagement (see Table 4).

Bully/victim problems and moral judgment

A chi-square test was computed to analyse associations between bully/victim problems and moral judgment. The analysis yielded a significant effect: $\chi^{2(503)}=7.98, p=.046$. The standardized residuals $(S R)$ show that bully-victims more frequently indicated that the aggressive behaviour is right than expected by chance: bully-victims: $n=4(20 \%$, $S R=2.5)$; bullies: $n=4(8.2 \% ; S R=0.7)$, victim: $n=2(4.3 \%, S R=-0.5)$, non-involved: $n=19(5.2 \%, S R=-0.7)$.

\section{Multivariate analyses}

To analyse whether bullies, bully-victims, victims, and non-involved adolescents differed regarding their morally responsible and morally disengaged justifications as well as moral and amoral emotions, linear mixed models were computed. Bully/victim categorization (four groups) served as the independent variable. Gender, age, and school type were entered as linear covariates. A linear mixed model analysis was conducted for each dependent variable separately (nine analyses in total).

As we had a clustered sample structure (students are nested within school classes), we used a multi-level approach. SPSS mixed models option with restricted maximum 
Table 4. Bivariate associations between all study variables

\begin{tabular}{|c|c|c|c|c|c|c|c|c|c|c|c|c|c|}
\hline & Age & $\begin{array}{l}\text { School } \\
\text { type }\end{array}$ & Bullying & Victimization & $\begin{array}{l}\text { Responsib. } \\
\text { total }\end{array}$ & Reciprocity & $\begin{array}{l}\text { Moral } \\
\text { rules }\end{array}$ & Empathy & $\begin{array}{c}\text { Moral } \\
\text { emotions }\end{array}$ & $\begin{array}{l}\text { Disengagem. } \\
\text { total }\end{array}$ & $\begin{array}{l}\text { Egocentric } \\
\text { diseng. }\end{array}$ & $\begin{array}{l}\text { Deviant } \\
\text { rules }\end{array}$ & $\begin{array}{l}\text { Amoral } \\
\text { emotions }\end{array}$ \\
\hline Sex (male) & $-.09^{*}$ & $-.14^{* *}$ & $.23^{* *}$ & $.13^{* *}$ & $-.27^{* *}$ & $-.19^{* *}$ & $-.25^{* *}$ & -.06 & -.05 & .00 & -.04 & $.09^{*}$ & .07 \\
\hline Age & & $.44^{* *}$ & .00 & $-.18^{* *}$ & $.1 I^{*}$ & .02 & $.18^{* *}$ & $-.09 *$ & $.12^{* *}$ & .02 & .02 & .05 & -.06 \\
\hline $\begin{array}{l}\text { (Higher) school } \\
\text { type }\end{array}$ & & & .01 & $-.15^{* *}$ & $.21^{* *}$ & -.02 & $.26^{* *}$ & -.01 & $.18^{* *}$ & .01 & .02 & .03 & -.08 \\
\hline Bullying & & & & $.33^{* *}$ & $-.09^{*}$ & $-.10^{*}$ & -.02 & $-.10^{*}$ & -.07 & $.15^{* *}$ & $.14^{* *}$ & $.09^{*}$ & $.09^{*}$ \\
\hline Victimization & & & & & $-.10^{*}$ & -.05 & $-.15^{* *}$ & .05 & -.06 & .01 & .03 & .01 & .01 \\
\hline $\begin{array}{l}\text { Responsible } \\
\text { justifications } \\
\text { total }\end{array}$ & & & & & & $.12^{* *}$ & $.75^{* *}$ & $.34^{* *}$ & $.38^{* *}$ & $-.19^{* *}$ & $-.14^{* *}$ & $-.15^{* *}$ & $-.24^{* *}$ \\
\hline Reciprocity & & & & & & & .01 & -.08 & -.01 & .02 & .04 & -.04 & -.01 \\
\hline Moral rules & & & & & & & & $-.17^{* *}$ & $.34^{* *}$ & $-.18^{* *}$ & $-.15^{* *}$ & $-.14^{* *}$ & $-.21^{* *}$ \\
\hline Empathy & & & & & & & & & .05 & -.04 & -.01 & -.04 & -.06 \\
\hline Moral emotions & & & & & & & & & & $-.44^{* *}$ & $-.46^{* *}$ & -.08 & $-.58^{* *}$ \\
\hline $\begin{array}{l}\text { Disengaged } \\
\text { justifications } \\
\text { total }\end{array}$ & & & & & & & & & & & $.92^{* *}$ & $.41^{* *}$ & $.52^{* *}$ \\
\hline $\begin{array}{l}\text { Egocentric } \\
\text { diseng. }\end{array}$ & & & & & & & & & & & & .05 & $.54^{* *}$ \\
\hline $\begin{array}{l}\text { Deviant rules } \\
\text { Amoral } \\
\text { emotions }\end{array}$ & & & & & & & & & & & & & .08 \\
\hline
\end{tabular}

Note. Pearson correlations: ${ }^{*} p<.05 ;{ }^{* *} p<.01$. 
Table 5. Results of the mixed linear model analyses predicting morally responsible justifications and moral emotion attributions

\begin{tabular}{|c|c|c|c|c|c|c|c|c|c|c|}
\hline & \multicolumn{8}{|c|}{ Justifications } & \multicolumn{2}{|c|}{$\begin{array}{l}\text { Emotion } \\
\text { attributions }\end{array}$} \\
\hline & \multicolumn{2}{|c|}{$\begin{array}{c}\text { Responsibility } \\
\text { total }\end{array}$} & \multicolumn{2}{|c|}{ Reciprocity } & \multicolumn{2}{|c|}{$\begin{array}{l}\text { Moral } \\
\text { rules }\end{array}$} & \multicolumn{2}{|c|}{ Empathy } & \multicolumn{2}{|c|}{ Moral } \\
\hline & $F$ & $p$ & $F$ & $p$ & $F$ & $p$ & $F$ & $p$ & $F$ & $P$ \\
\hline $\begin{array}{l}\text { (Fixed) } \\
\text { intercept }\end{array}$ & 20.72 & .00 & 0.05 & .82 & 5.84 & .02 & 13.34 & .00 & 0.00 & .98 \\
\hline $\begin{array}{l}\text { Bully/victim } \\
\text { category }\end{array}$ & 1.81 & .14 & 2.16 & .09 & 3.18 & .02 & 3.09 & .03 & 1.33 & .26 \\
\hline Sex (male) & 30.37 & .00 & 16.78 & .00 & 26.39 & .00 & 1.72 & .19 & 0.01 & .83 \\
\hline Age & 0.00 & .97 & 0.28 & .60 & 1.36 & .25 & 4.17 & .05 & 1.46 & .24 \\
\hline $\begin{array}{c}\text { School type } \\
\text { (higher) }\end{array}$ & 9.49 & .00 & 1.77 & .18 & 10.92 & .00 & 1.10 & .30 & 6.05 & .02 \\
\hline
\end{tabular}

likelihood estimation (REML) was used to analyse the data (Heck, Thomas, \& Tabata, 2010). In addition to the above-described fixed effects, classroom was entered as random effect (random intercept model). The random effect of classroom was not significant in any analyses, indicating no main effects of the clustering.

\section{Morally responsible justifications}

Significant effects of bully/victim categorization emerged regarding the production of moral rules and empathy (see Table 5). Pairwise comparisons showed that victims produced empathy justifications more frequently than all other participants, and referred to moral rules less frequently than bullies and non-involved students (see Table 7).

Moreover, the analyses yielded significant effects of sex, age, and school type: Males produced fewer morally responsible justifications $(B=-0.42, p<.001)$, less reciprocity $(B=-0.12, p<.001)$, and fewer moral rules $(B=-0.30, p>.001)$ than female participants. The older the participants, the fewer empathy justifications were produced $(B=-0.04, p<.05)$. The higher the education level of the school (school type), the more morally responsible justifications $(B=0.18, p=.004)$ were produced by the students, especially more moral rules $(B=0.19, p<.05)$.

\section{Morally disengaged justifications}

Significant effects of bully/victim categorization also emerged regarding moral disengagement (total; see Table 6). Pairwise comparisons showed that bullies produced significantly more morally disengaged justifications than non-involved students (see Table 7). The socio-demographic variables did not reach significance.

\section{Moral and amoral emotions}

The multivariate analyses regarding emotion attribution yielded no significant effects for bully/victim categorization, sex, and age (see Tables 5 and 6). A significant effect of school type emerged: The higher the achievement level of the school, the more moral emotions were shown by the students $(B=0.13, p=.018)$. 
Table 6. Results of the mixed linear model analyses predicting morally disengaged justifications and amoral emotion attributions

\begin{tabular}{|c|c|c|c|c|c|c|c|c|}
\hline & \multicolumn{6}{|c|}{ Justifications } & \multirow{2}{*}{\multicolumn{2}{|c|}{$\begin{array}{c}\begin{array}{c}\text { Emotion } \\
\text { attributions }\end{array} \\
\begin{array}{c}\text { Amoral } \\
\text { emotions }\end{array}\end{array}$}} \\
\hline & \multicolumn{2}{|c|}{$\begin{array}{c}\text { Disengaged } \\
\text { justifications }\end{array}$} & \multicolumn{2}{|c|}{$\begin{array}{l}\text { Egocentric } \\
\text { diseng. }\end{array}$} & \multicolumn{2}{|c|}{$\begin{array}{c}\text { Deviant } \\
\text { rules }\end{array}$} & & \\
\hline & $F$ & $p$ & $F$ & $P$ & $F$ & $p$ & $F$ & $p$ \\
\hline $\begin{array}{l}\text { (Fixed) } \\
\text { intercept }\end{array}$ & 6.19 & .02 & 7.95 & .01 & 0.08 & .78 & 11.61 & .00 \\
\hline $\begin{array}{l}\text { Bully/victim } \\
\text { category }\end{array}$ & 3.64 & .01 & 2.49 & .06 & 1.37 & .25 & 1.73 & .16 \\
\hline Sex (male) & 0.09 & .76 & 1.14 & .29 & 3.56 & .06 & 1.16 & .28 \\
\hline Age & 0.04 & .84 & 0.00 & .95 & 0.92 & .34 & 0.49 & .49 \\
\hline $\begin{array}{l}\text { School type } \\
\text { (higher) }\end{array}$ & 0.03 & .87 & 0.15 & .70 & 0.18 & .67 & 0.89 & .35 \\
\hline
\end{tabular}

Table 7. Estimated marginal means of morally responsible and morally disengaged justifications by bully/victim categorization

\begin{tabular}{lcccc}
\hline Justifications & $\begin{array}{c}\text { Bully } \\
(n=74)\end{array}$ & $\begin{array}{c}\text { Bully-victim } \\
(n=20)\end{array}$ & $\begin{array}{c}\text { Victim } \\
(n=50)\end{array}$ & $\begin{array}{c}\text { Non-involved } \\
(n=372)\end{array}$ \\
\hline $\begin{array}{l}\text { Morally responsible } \\
\text { Responsibility total }\end{array}$ & $1.55^{\mathrm{a}}$ & $1.62^{\mathrm{a}}$ & $1.51^{\mathrm{a}}$ & $1.73^{\mathrm{a}}$ \\
Reciprocity & $0.07^{\mathrm{a}}$ & $0.01^{\mathrm{a}}$ & $0.06^{\mathrm{a}}$ & $0.14^{\mathrm{a}}$ \\
Moral Rules & $1.24^{\mathrm{a}}$ & $1.27^{\mathrm{a}, \mathrm{b}}$ & $0.88^{\mathrm{b}}$ & $1.28^{\mathrm{a}}$ \\
$\quad$ Empathy & $0.36^{\mathrm{a}, \mathrm{c}}$ & $0.25^{\mathrm{a}, \mathrm{c}}$ & $0.66^{\mathrm{b}}$ & $0.47^{\mathrm{c}}$ \\
Morally disengaged & & & & \\
$\quad$ Disengagement total & $1.04^{\mathrm{a}}$ & $0.75^{\mathrm{ab}}$ & $0.83^{\mathrm{ab}}$ & $0.75^{\mathrm{b}}$ \\
Egocentric diseng. & $0.91^{\mathrm{a}}$ & $0.70^{\mathrm{ab}}$ & $0.79^{\mathrm{ab}}$ & $0.70^{\mathrm{b}}$ \\
Deviant rules & $0.14^{\mathrm{a}}$ & $0.09^{\mathrm{a}}$ & $0.10^{\mathrm{a}}$ & $0.07^{\mathrm{a}}$ \\
\hline
\end{tabular}

Note. Cells show estimated marginal means, the value of the covariates were set to: school type $=.67$; age $=15.16$; sex $=.43 .{ }^{a-d}$ Means in the same row that do not share superscripts differ significantly from each other (LSD).

\section{Gender and age interaction effects}

In a second step, the analyses were repeated to investigate whether gender and age moderated the associations reported above (see Tables 5 and 6). None of the Gender $\times$ Bully/victim categorization effects reached significance, indicating that the reported effects apply both to boys and girls.

Age was included in the analysis as a linear variable. To facilitate interpretation, age was linearly transformed (minimum score, i.e., age $12=0$ ). The above reported main effects of bully/victim categorization were not moderated by age. However, two additional Age $\times$ Bully/victim categorization effects emerged regarding moral responsibility, $F(3,500)=4.17, p=.006$, and deviant rules, $F(3,503)=4.98, p=$ .002 . Moreover, the main effect of bully/victim categorization regarding deviant rules reached significance, $F(3,500)=3.58, p=.014$. Parameter estimates indicate that there 
were specific age effects for the group of victims only. Among victims, the production of morally responsible justifications decreased with age (Victims: $B=-0.26 ; p=.001$; all other groups: $B>-0.02$, ns). Regarding deviant rules, parameter estimates indicate that at the intercept (=age 12 ), victim produce fewer deviant rules than non-involved students $(B=-0.23 ; p=.027)$. However, the frequency of deviant rules increased with age (Victims: $B=0.11 ; p<.001$; all other groups: $B<0.002, \mathrm{~ns}$ ).

\section{Discussion}

This study investigated moral reasoning and emotion attributions in bullies, victims, and bully-victims among Swiss adolescents. The first goal was to examine the role of different facets of morally disengaged and morally responsible reasoning as well as moral and amoral emotion attributions for bullying behaviour. The second goal was to explore how victimization is related to moral reasoning and emotion attributions.

\section{Bullying, moral reasoning, and moral emotions}

As expected, our first main finding is that adolescents involved in bullying showed the highest levels of morally disengaged reasoning. This finding is consistent with previous developmental research revealing a positive association between bullying in adolescence and morally disengaged or egocentric reasoning strategies (e.g., Menesini et al., 2003). Our finding is also in keeping with research that interconnects aggression and moral reasoning. For example, Gasser and Keller (2009) showed that 7- and 8-year-old bullies were less likely to provide moral reasons for their emotion attributions than were prosocial children. Thus, when compared to a control group, aggressive children seem to be more likely to focus on personal gain or sanctions than on moral issues to justify their emotion attributions (Arsenio \& Fleiss, 1996; Hughes \& Dunn, 2000).

Although we found a positive relation between bullying and amoral (i.e., positive emotions such as being proud or happy) emotion attributions on the bivariate level, this effect disappeared in the multivariate findings. Additionally, there was no negative relation between bullying and moral emotions (i.e., negative emotions such as being ashamed or anxious). Taken together, the weak relation between bullying and moral emotion attributions may indicate that the justification behind their respective emotion attributions may tell more about the underlying motive than the emotion attribution itself (Gasser \& Keller, 2009). Although moral emotion attributions are indicative of children's aggressive behaviour (Arsenio et al., 2006), and some studies have documented negative relations between aggression and moral emotion attributions in adolescence (Arsenio, Adams, \& Gold, 2009; Krettenauer \& Eichler, 2006; Malti \& Krettenauer, 2011), these differences might in part be due to methodological variations across studies. For example, the Arsenio et al. (2009) study used an emotion chip methodology to assess emotion attributions in relation to aggression, and the Krettenauer and Eichler (2006) study measured strength of self-attributed negative emotions and its link to aggression. Possibly, emotion attributions as assessed in our study need to be investigated simultaneously with moral reasoning to be predictive for adolescents' bullying (see Gasser \& Keller, 2009), owing in part to increased cognitive awareness in older children's and adolescents' repertoire of justifications of negative emotion attributions, allowing for a broader range of justifications to explain the attributed negative or positive emotions. This, in turn, makes an analysis of the justifications necessary to understand why adolescents have 
attributed negative (or positive) emotions to a transgressor and thus to detect meaningful relationships between bullying and moral responding.

Regarding the findings on moral reasoning, the present results indicated that students mainly gave morally responsible arguments. Most moral disengagement justifications were produced when students were asked how the hypothetical perpetrator felt, probing their representation of a (potentially happy) victimizer. When producing morally disengaged justifications (e.g., to explain why the hypothetical victimizer feels happy), students mainly used egocentric hedonistic justifications (i.e., the perpetrator feels good because she fulfilled some hedonistic needs). These findings are consistent with other developmental studies on moral reasoning (Gutzwiller-Helfenfinger et al., 2011; Menesini et al., 2003) showing that hedonistic (i.e., egocentric disengagement) reasoning is much more common than specific moral disengagement strategies (deviant rules). Thus, adolescents may judge their own hedonistic goals as being more important than the victim's suffering, but do not have a pronounced (internalized) moral disengagement pattern (i.e., deviant rules such as blaming the victim). These findings may support the importance of fostering empathy with the victim's perspective as an important preventive strategy against bullying. However, it is important to note that the hypothetical scenario we used in the current study was a one-time act of relational aggression. Maybe specific moral disengagement strategies might be shown more frequently by adolescents when confronted by a more severe bullying scenario.

In line with other studies we found that females demonstrated higher levels of moral reasoning than males (e.g., Malti et al., in press). However, the gender difference in moral disengagement only emerged regarding the subscale of deviant rules and did not reach significance in the multivariate analyses. This may indicate that females, still facing social inequality in Switzerland, are sensitized towards moral issues (Malti et al., in press). Regarding age, we found no significant increase in moral reasoning (or decrease in moral disengagement, respectively). In contrast, younger students produced more victim-oriented justifications (i.e., empathy) than did older students. As younger students were also more frequently victimized, the higher level of empathy might be related to their own experiences of being victims.

Furthermore, we found that in schools with lower achievement levels, students showed fewer morally responsible justifications, especially moral rules, and less moral emotions than students in schools with higher achievement levels. This latter finding is important considering that moral disengagement is also important as a group-level characteristic (Hymel et al., 2010). For example, a study by Gutzwiller-Helfenfinger and Alsaker (2010) found that the classroom level of pro-disengagement attitude, as measured by a Swiss version of Bandura's scale, was a significant predictor of individual bullying.

The fact that no classroom effects on moral development and bullying were found is interesting because there is a growing body of research indicating that classroom effects are important in children's experiences of aggression and victimization (e.g., Ahn, Garandeau, \& Rodkin, 2010). However, classroom effects on children's bullying/victimization experiences are usually assessed by explicitly tapping into classroom functioning, that is, the presence or absence of pro-bullying norms (e.g., Salmivalli \& Voeten, 2004) or aspects of classroom structure like, for example, embeddedness (Ahn et al., 2010). The analyses performed in the present study took into account potential differences between classrooms, but specific aspects of classroom functioning or structure were not addressed. This will certainly need to be done in future research. 


\section{Victimization, moral reasoning, and moral emotions}

Our findings indicate that adolescents who were frequently victimized (but are not aggressive themselves) had higher levels of empathy with the hypothetical victim. This finding is new, and we did not know (a priori) whether non-aggressive victims would be morally sensitized towards issues of fairness or instead show a tendency towards moral disengagement, given their negative past experiences in interpersonal conflict situations. Our study supports the claim that people with low status in the social hierarchy such as victims in peer groups may be morally sensitized to issues of unfairness and inequality (Turiel, 2002). Victims are on the receiving end of interpersonal aggression and know what being victimized feels like. Accordingly, victims seem to have no problems empathizing with other victims. For preventive purposes, this finding may indicate that adolescents also need to experience the role of the victim (e.g., in role playing scenarios, Gutzwiller-Helfenfinger, 2008).

Nevertheless, we also found an interaction between age group and victimization in predicting morally responsible and morally disengaged justifications. Thus, the older the victims, the more they reasoned with reference to deviant rules and the less they reasoned with reference to morally responsible rules. Only few students were categorized as victims in the oldest age groups, which is in line with general age trends of bullying and victimization (e.g., Eslea \& Rees, 2001; Pellegrini \& Long, 2002). Thus, older victims may be chronic victims, whereas victims in the younger age groups might not be in a stable victim role yet. It is likely that the negative peer experiences of chronically victimized children cause moral desensitization. Perhaps they begin to construct the world as an unjust place. More research is needed to further investigate whether being victimized over long periods of time may lead to moral regression.

It is important to note that the latter findings were only found for non-aggressive victims. Results of the present study underscore the need to differentiate between nonaggressive and aggressive victims. Bully-victims also reported significantly lower levels of empathy than victims, and they reported more frequently that it is okay to violate the moral rule. Although the latter finding needs to be interpreted with caution because of a small sample size, bully-victims may be particularly at risk for developing moral detachment. As bully-victims also suffer from socio-cognitive deficits, especially the understanding of another's mind (e.g., Gasser \& Keller, 2009), a competence central for moral understanding, this may make them especially vulnerable when it comes to the development of empathic reasoning. Using the same vignette in an interview with younger children, Gutzwiller-Helfenfinger et al. (2011) showed that being a bully-victim at age five predicted lower moral understanding at age nine. Accordingly, both victims and bully-victims might share higher levels of moral detachment, whereas victims - in contrast to bully-victims - still have higher moral understanding. This suggests differential developmental trajectories for these two categories of victims, a hypothesis that needs to be addressed in future research.

\section{Strengths, limitations, and implications for future research}

A main strength of the study is that we focused on bullies, aggressive and non-aggressive victims when investigating links between peer group status, moral reasoning, and moral emotion attributions. Previous research has been limited to links between bullying and moral disengagement. A second strength of the study is the use of a production measure to assess adolescents' moral justifications instead of a self-report questionnaire on moral disengagement. This allowed us to investigate the relative importance of specific moral 
disengagement strategies relative to other kinds of moral justifications, particularly morally responsible justifications, yielding a more differentiated perspective on potential associations between victimization and moral reasoning.

This study is not without limitations. First, we only used one vignette in the current study (i.e., a relational aggression scenario). However, a study with 9-year-old children using a similar relational aggression vignette (Gutzwiller-Helfenfinger et al., 2011) found strong associations between personal involvement in bullying in the context of a specific aggression scenario rather than in the context of a refusal of help scenario. Thus, the use of context-specific scenarios (i.e., aggressive or bullying behaviour) seems quite adequate to investigate links with bullying behaviours.

Second, our scenario described an aggressive act including a girl aggressing (relationally) against a boy. Since bullying typically occurs within gender (i.e., boys are bullied by mainly boys; see Boulton \& Underwood, 1992; Mynard, Joseph, \& Alexander, 2000), this context limits the generalizability of the findings. Nevertheless, a study by Wolke, Woods, Bloomfield, and Karstadt (2001) indicates that boys may be bullied by girls too. As the aggression form used by the female victimizer was gender normative (Crick, 1997), the scenario describes a plausible social situation for adolescents. As we did not find significant gender interactions in the multivariate analyses, the findings of our study apply to boys and girls. Future research is needed to investigate if there are contextspecific differences in adolescents' judgments and emotion attributions about moral transgressions, such as the gender of the aggressor and victim and aggression form.

Third, we only examined cross-sectional associations. Therefore, we do not know whether moral reasoning is merely a correlate of bullying, or rather assumes a causal or moderating role. Furthermore, there is a lack of findings regarding the association between moral reasoning, moral emotions, and moral values. Bandura's theory (2002) was developed to explain the fact that people who profess to have high moral standards nevertheless may act inhumanly under certain conditions and not even feel guilty about it. Therefore, the question emerges as to whether moral disengagement is really an indicator of a person's impaired moral development (i.e., does moral disengagement lead to 'moral corrosion' and a detachment from moral emotions and moral values) or whether it is a psychological process that pursues mainly self-serving goals in order to rationalize one's own negative behaviour (i.e., to behave 'badly' without feeling guilty). Future studies should investigate longitudinal associations between bullying behaviour, moral reasoning, moral emotions, and moral values. In addition, research examining the links between victimization experiences and moral responsibility seems warranted. As victims of bullying often develop severe emotional problems (e.g., Malti, Perren et al., 2010; Perren et al., 2010), it seems important to understand if and how moral development can help protect them against dysfunctional developmental pathways.

\section{References}

Ahn, H.J., Garandeau, C. F., \& Rodkin, P. C. (2010). Effects of classroom embeddedness and density on the social status of aggressive and victimized children. Journal of Early Adolescence, 30(1), 76-101.

Arsenio, W. F., Adams, E., \& Gold, J. (2009). Social information processing, moral reasoning, and emotion attributions: Relations with adolescents' reactive and proactive aggression. Child Development, 80(6), 1739-1755.

Arsenio, W. F., \& Fleiss, K. (1996). Typical and behaviourally disruptive children's understanding of the emotional consequences of socio-moral events. British Journal of Developmental Psychology, 14, 173-186. 
Arsenio, W. F., Gold, J., \& Adams, E. (2006). Children's conceptions and displays of moral emotions . In M. Killen \& J. Smetana (Eds.), Handbook of moral development (pp. 581-609). Mahwah, N.J.: Lawrence Erlbaum.

Arsenio, W. F., \& Lemerise, E. A. (2004). Aggression and moral development: Integrating social information processing and moral domain models. Child Development, 75(4), 987-1002.

Bandura, A. (2002). Selective moral disengagement in the exercise of moral agency. Journal of Moral Education, 31(2), 101-119.

Boulton, M. J., \& Underwood, K. (1992). Bully/victim problems among middle school children. British Journal of Educational Psychology, 62(1), 73-87.

Caprara, G. V., Pastorelli, C., \& Bandura, A. (1995). La misura del disimpegno morale in età evolutiva [The measurement of moral disengagement in children]. Età Evolutiva, 46, 18-29.

Crick, N. R. (1997). Engagement in gender normative versus nonnormative forms of aggression: Links to social-psychological adjustment. Developmental Psychology, 33(4), 610-617.

Eslea, M., \& Rees, J. (2001). At what age are children most likely to be bullied at school? Aggressive Behavior, 27(6), 419-429.

Garner, P. W., \& Lemerise, E. A. (2007). The roles of behavioral adjustment and conceptions of peers and emotions in preschool children's peer victimization. Development and Psychopathology, 19(1), 57-71.

Gasser, L., \& Keller, M. (2009). Are the competent the morally good? Perspective taking and moral motivation of children involved in bullying. Social Development, 18(4), 798-816.

Gavaghan, M. P., Arnold, K. D., \& Gibbs, J. C. (1983). Moral judgment in delinquents and nondelinquents: Recognition versus production measures. Journal of Psychology, 114, 267274.

Gini, G. (2006). Social cognition and moral cognition in bullying: What's wrong? Aggressive Behavior, 32(6), 528-539.

Graham, S., \& Juvonen, J. (1998). Self-blame and peer victimization in middle school: An attributional analysis. Developmental Psycbology, 34(3), 587-599.

Gutzwiller-Helfenfinger, E. (2008). Die Wirkung von erweitertem Rollenspiel auf soziale Perspektivenübernahme und antisoziales Verhalten [The impact of role-playing on social perspective taking and antisocial behavior]. In T. Malti \& S. Perren (Eds.), Soziale Kompetenz bei Kindern und Jugendlichen: Entwicklungsprozesse und Förderungsmöglichkeiten. Stuttgart: Kohlhammer.

Gutzwiller-Helfenfinger, E., \& Alsaker, F. (2010). Moral disengagement and bully/victim problems in adolescence: The role of contextual factors. Paper presented at the Biennial Meeting of the Society for Research in Adolescence, March, 11-13, 2010. New York: Routledge.

Gutzwiller-Helfenfinger, E., Malti, T., Groeben, M., Stadelmann, S., von Klitzing, K., \& Perren, S. (2011). Bully/victim problems from kindergarten to age 9: Associations with moral disengagment and moral responsiblity. Manuscript in preparation.

Heck, R. H., Thomas, S. L., \& Tabata, L. N. (2010). Multilevel and longitudinal modeling with IBM SPSS. New York: Routledge.

Hughes, C., \& Dunn, J. (2000). Hedonism or empathy?: Hard-to-manage children's moral awareness and links with cognitive and maternal characteristics. British Journal of Developmental Psycbology, 18(2), 227-245.

Hymel, S., Rocke-Henderson, N., \& Bonanno, R. A. (2005). Moral disengagement: A framework for understanding bullying among adolescents. Journal of Social Sciences, (Special Issue No. 8), 33-43.

Hymel, S., Schonert-Reich1, K. A., Bonanno, R. A., Vaillancourt, T., \& Henderson, N. R. (2010). Bullying and morality: Understanding how good kids can behave badly. In S. R. Jimerson, S. M. Swearer, \& D. Espelage (Eds.), International handbook of school bullying. Mahwah, N.J.: Lawrence Erlbaum Associates, Inc.

Keller, M. (2004). Self in relationships. In D. K. Lapsley \& D. Narvaez (Eds.), Morality, self, and identity (pp. 269-300). Mahwah, N.J.: Lawrence Erlbaum. 
Keller, M., Edelstein, W., Schmid, C., Fang, F.X., \& Fang, G. (1998). Reasoning about responsibilities and obligations in close relationships: A comparison across two cultures. Developmental Psychology, 34, 731-741.

Killen, M., Lee-Kim, J., McGlothlin, H., \& Stangor, C. (2002). How children and adolescents evaluate gender and racial exclusion. Monographs of the Society for Research in Child Development, Serial No. 271, Vol. 67(4). Oxford: Blackwell.

Krettenauer, T., \& Eichler, D. (2006). Adolescents' self-attributed moral emotions following a moral transgression: Relations with delinquency, confidence in moral judgment and age. British Journal of Developmental Psychology, 24(3), 489-506.

Krettenauer, T., Malti, T., \& Sokol, B. W. (2008). The development of moral emotion expectancies and the happy victimizer phenomenon: A critical review of theory and application. European Journal of Developmental Science, 2(3), 221-235.

Malti, T., Gasser, L., \& Gutzwiller-Helfenfinger, E. (2010). Children's interpretive understanding, moral judgments, and emotion attributions: Relations to social behaviour. British Journal of Developmental Psychology, 28(2), 275-292.

Malti, T., Gummerum, M., Keller, M., \& Buchmann, M. (2009). Children's moral motivation, sympathy, and prosocial behavior. Child Development, 80(2), 442-460.

Malti, T., \& Keller, M. (2009). The relation of elementary-school children's externalizing behaviour to emotion attributions, evaluation of consequences, and moral reasoning. European Journal of Developmental Psychology, 6(5), 592-614.

Malti, T., Killen, M., \& Gasser, L. (in press). Social judgments and emotion attributions about exclusion in Switzerland. Child Development.

Malti, T., \& Krettenauer, T. (2011). The role of moral emotion attributions in children's and adolescents' pro- and antisocial bebavior: A meta-analytic study. Manuscript in preparation.

Malti, T., Perren, S., \& Buchmann, M. (2010). Children's peer victimization, empathy, and emotional symptoms. Child Psycbiatry and Human Development, 41(1), 98-113.

Menesini, E., Sanchez, V., Fonzi, A., Ortega, R., Costabile, A., \& Lo Feudo, G. (2003). Moral emotions and bullying: A cross-national comparison of differences between bullies, victims and outsiders. Aggressive Bebavior, 29(6), 515-530.

Mynard, H., Joseph, S., \& Alexander, J. (2000). Peer-victimisation and posttraumatic stress in adolescents. Personality and Individual Differences, 29(5), 815-821.

Nunner-Winkler, G. (1999). Development of moral understanding and moral motivation. In F. E. Weinert \& W. Schneider (Eds.), Individual development from 3 to 12: Findings from the Munich longitudinal study (pp. 253-290). New York, NY: Cambridge University Press.

Olweus, D. (1991). Bully/victim problems among schoolchildren. Basic facts of a school based intervention program. In D. J. Pepler \& K. H. Rubin (Eds.), The development and treatment of childhood aggression (pp. 411-448). Hillsdale, N.J.: Lawrence Erlbaum.

Paciello, M., Fida, R., Tramontano, C., Lupinetti, C., \& Caprara, G. V. (2008). Stability and change of moral disengagement and its impact on aggression and violence in late adolescence. Child Development, 79(5), 1288-1309.

Pellegrini, A. D., \& Long, J. D. (2002). A longitudinal study of bullying, dominance, and victimization during the transition from primary school through secondary school. Britisb Journal of Developmental Psychology, 20(2), 259-280.

Perren, S., \& Alsaker, F. D. (2006). Social behavior and peer relationships of victims, bully-victims, and bullies in kindergarten. Journal of Child Psychology and Psycbiatry, 47(1), 45-57.

Perren, S., Dooley, J., Shaw, T., \& Cross, D. (2010). Bully/victim problems in schools and in cyberspace: Associations with depressive symptoms in Swiss and Australian adolescents. Child and Adolescent Psychiatry and Mental Health, 4:28.

Perren, S., \& Hornung, R. (2005). Bullying and delinquency in adolescence: Victims' and perpetrators' family and peer relations. Swiss Journal of Psychology, 64(1), 51-64.

Pornari, C. D., \& Wood, J. (2010). Peer and cyber aggression in secondary school students: The role of moral disengagement, hostile attribution bias, and outcome expectancies. Aggressive Behavior, 36(2), 81-94. 
Salmivalli, C., \& Voeten, M. (2004). Connections between attitudes, group norms, and behaviour in bullying situations. International Journal of Bebavioral Development, 28(3), 246.

Stams, G. J., Brugman, D., Deković, M., van Rosmalen, L., van der Laan, P., \& Gibbs, J. C. (2006). The moral judgment of juvenile delinquents: A meta-analysis. Journal of Abnormal Cbild Psycbology, 34(5), 692-708.

Stassen Berger, K. (2007). Update on bullying at school: Science forgotten? Developmental Review, $27(1), 90-126$.

Sutton, J., Smith, P. K., \& Swettenham, J. (1999). Social cognition and bullying: Social inadequacy or skilled manipulation. British Journal of Developmental Psychology, 17, 435-450.

Tangney, J. P., \& Dearing, R. L. (2002). Gender differences in morality. In R. F. Bornstein \& M. Masling (Eds.), Empirical studies in psychoanalytic theories (Vol. 10): The psychodynamics of gender and gender role (pp. 251-269). Washington, DC: American Psychological Association.

Tisak, M. S., Tisak, J., \& Goldstein, S. E. (2006). Aggression, delinquency, and morality: A socialcognitive perspective. In M. Killen \& J. Smetana (Eds.), Handbook of moral development (pp. 611-629). Mahwah, N.J.: Lawrence Erlbaum.

Turiel, E. (2002). The culture of morality: Social development, context, and conflict. Cambridge: Cambridge University Press.

Wolke, D., Woods, S., Bloomfield, L., \& Karstadt, L. (2001). Bullying involvement in primary school and common mental health problems. Arcbives of Disease in Childbood, 85(3), 197-201. 